\title{
ARTICLE
}

OPEN

\section{Dietary Nitrate Enhances the Contractile Properties of Human Skeletal Muscle}

\author{
Andrew R. Coggan ${ }^{1,2}$ and Linda R. Peterson 3,4 \\ Departments of ${ }^{1}$ Kinesiology and ${ }^{2}$ Cellular and Integrative Physiology, Indiana University Purdue University \\ Indianapolis, Indianapolis, IN; and Departments of ${ }^{3}$ Medicine and ${ }^{4}$ Radiology, Washington University School of \\ Medicine, St. Louis, MO
}

COGGAN, A.R. and L.R. PETERSON. Dietary nitrate enhances the contractile properties of human skeletal muscle. Exerc. Sport Sci. Rev., Vol. 46, No. 4, pp. 254-261, 2018. Dietary nitrate, a source of nitric oxide (NO), improves the contractile properties of human muscle. We present the hypothesis that this is due to nitrosylation of the ryanodine receptor and increased NO signaling via the soluble guanyl cyclase-cyclic guanosine monophosphate-protein kinase $\mathrm{G}$ pathway, which together increase the free intracellular $\mathrm{Ca}^{2+}$ concentration along with the $\mathrm{Ca}^{2+}$ sensitivity of the myofilaments themselves. Key Words: dietary nitrate, nitric oxide, muscle contractile function, free intracellular calcium, calcium sensitivity, ryanodine receptor, cyclic guanosine monophosphate

\section{Key Points}

- Ingestion of nitrate $\left(\mathrm{NO}_{3}^{-}\right)$, found in green leafy vegetables and especially beets, increases the production of nitric oxide (NO).

- Acute or chronic $\left(\mathrm{NO}_{3}^{-}\right)$intake also improves muscle contractile function in a variety of subject populations, including healthy young and middle-aged individuals, athletes, patients with heart failure, and the elderly.

- Precisely how dietary $\left(\mathrm{NO}_{3}^{-}\right)$intake enhances the contractile properties of human muscle is still unclear.

- We hypothesize that such improvements are the result of increased $\mathrm{NO}$ bioavailability and hence changes in $\mathrm{Ca}^{2+}$ signaling in muscle.

\section{INTRODUCTION}

In recent years, a burgeoning number of studies have examined the effects of dietary nitrate $\left(\mathrm{NO}_{3}{ }^{-}\right)$on various physiological responses. This is because it is now recognized that inorganic $\mathrm{NO}_{3}{ }^{-}$can be a significant source of nitric oxide

Address for correspondence: Andrew R. Coggan, Ph.D., FACSM, Department of Kinesiology, Indiana University Purdue University Indianapolis, IF 101C, 250 University Blvd, Indianapolis, IN 46202 (E-mail: acoggan@iupui.edu).

Accepted for publication: July 3, 2018.

Editor: Stephen E. Alway, Ph.D., FACSM.

\section{1-6331/4604/254-261}

Exercise and Sport Sciences Reviews

DOI: 10.1249/JES.0000000000000167

Copyright (c) 2018 The Author(s). Published by Wolters Kluwer Health, Inc. on behalf of the American College of Sports Medicine. This is an open-access article distributed under the terms of the Creative Commons Attribution-Non Commercial-No Derivatives License 4.0 (CCBY-NC-ND), where it is permissible to download and share the work provided it is properly cited. The work cannot be changed in any way or used commercially without permission from the journal.
$(\mathrm{NO})$ in the body ((1); see as follows). Because $\mathrm{NO}$ is a potent vasodilator, work in this area originally focused on changes in blood pressure (e.g., (2)). In 2007, however, Larsen et al. (3) reported that ingestion of $\mathrm{NO}_{3}{ }^{-}$at a dose of $100 \mu \mathrm{mol} \cdot \mathrm{kg}^{-1}$ per day for $3 \mathrm{~d}$ lowered the steady-state rate of $\mathrm{O}_{2}$ uptake $\left(\mathrm{VO}_{2}\right)$ during submaximal exercise. This $\mathrm{O}_{2}$ sparing effect of $\mathrm{NO}_{3}{ }^{-}$supplementation (often in the form of beetroot juice (BRJ)) has since been replicated in many, albeit not all (4), subsequent investigations, and seems to be especially evident in untrained subjects and during higher intensity exercise (cf. (5) for review). Dietary $\mathrm{NO}_{3}{ }^{-}$also has been shown to enhance muscle blood flow during exercise in both rats (6) and humans (7). At least in rats, the relative increase in flow is greatest in primarily fast-twitch muscles with lower baseline blood flows, but is also present, albeit to a lesser extent, in primarily slow-twitch muscles (6). Presumably as a consequence of these changes in $\mathrm{O}_{2}$ demand and supply, and hence in muscle energetics, dietary $\mathrm{NO}_{3}{ }^{-} \mathrm{im}$ proves endurance performance, as measured by average power, or, conversely, time-to-completion, during highintensity, time trial-type exercise tests by $\sim 2 \%(8,9)$. Because of the shallow slope of the exercise intensity-duration relationship beyond the first few minutes, time-to-fatigue during constant-intensity exercise may be enhanced by up to $16 \%$ $(5,6)$. For additional discussion of the effects of dietary $\mathrm{NO}_{3}{ }^{-}$ on the responses to endurance exercise, readers are referred to these recent reviews $(5,8,9)$.

More recently, dietary $\mathrm{NO}_{3}^{-}$(or nitrite $\left(\mathrm{NO}_{2}^{-}\right)$) also has been shown to enhance the inherent contractile properties of human muscle (10-20). Positive effects have been found in a wide range of subjects, that is, younger untrained individuals $(10-12,14)$, trained athletes $(13,15-17)$, patients with heart failure (HF) (18), and the elderly $(19,20)$, and can occur in the absence of changes in submaximal $\mathrm{VO}_{2}$ in the same population and 
even in some of the same individuals (i.e., (4) vs (18)). Furthermore, $\mathrm{NO}_{3}{ }^{-}$-induced improvements in muscle contractility have been observed even when resistance to fatigue during highintensity exercise is unaltered $(11,13-15)$. These results suggest that the effects of dietary $\mathrm{NO}_{3}{ }^{-}$on muscle contractile properties and on $\dot{\mathrm{VO}}_{2}$ /blood flow/energetics may be due to different physiological/biochemical mechanisms, reflecting the widely varying actions of $\mathrm{NO}$ in various tissues, including muscle.

The purpose of the present article is to review the previously mentioned studies of the influence of dietary $\mathrm{NO}_{3}{ }^{-}$on the contractile properties of human muscle and to discuss possible mechanisms accounting for such effects. Although animal data are considered, especially in formulating our mechanistic hypotheses, we focus primarily upon humans because 1) most studies of the effects of $\mathrm{NO}_{3}{ }^{-}$intake on muscle function have been performed in people and 2) there are significant differences between rodents and humans in dietary $\mathrm{NO}_{3}{ }^{-}$metabolism (21), $\mathrm{NO}_{3}{ }^{-}$-induced changes in muscle protein expression $(12,22)$, fiber type-specific regulation of muscle contraction (23), and
NO production (24), etc., that could influence the results of such research. As will be discussed, it is our hypothesis that dietary $\mathrm{NO}_{3}{ }^{-}$acutely enhances human muscle function by simultaneously increasing both the free intracellular $\mathrm{Ca}^{2+}$ concentration $\left(\left[\mathrm{Ca}^{2+}\right]_{\mathrm{i}}\right)$ during contractions and the $\mathrm{Ca}^{2+}$ sensitivity of the myofilaments themselves (Figure). These twin effects are hypothesized to result from nitrosylation of the ryanodine receptor (RyR) along with increased NO signaling via the canonical soluble guanyl cyclase (sGC)-cyclic guanosine monophosphate (cGMP)-protein kinase $\mathrm{G}$ (PKG) pathway. Together, these two mechanisms could explain the dietary $\mathrm{NO}_{3}{ }^{-}$-induced changes in human muscle contractile properties that have been reported.

\section{NO Production in Muscle}

Most NO in the body is produced by conversion of L-arginine to citrulline, a reaction catalyzed by NO synthase (NOS) and requiring $\mathrm{O}_{2}$ as well as other substrates and cofactors. NOS exists in three isoforms, that is, neuronal (nNOS, or NOS-1), inducible

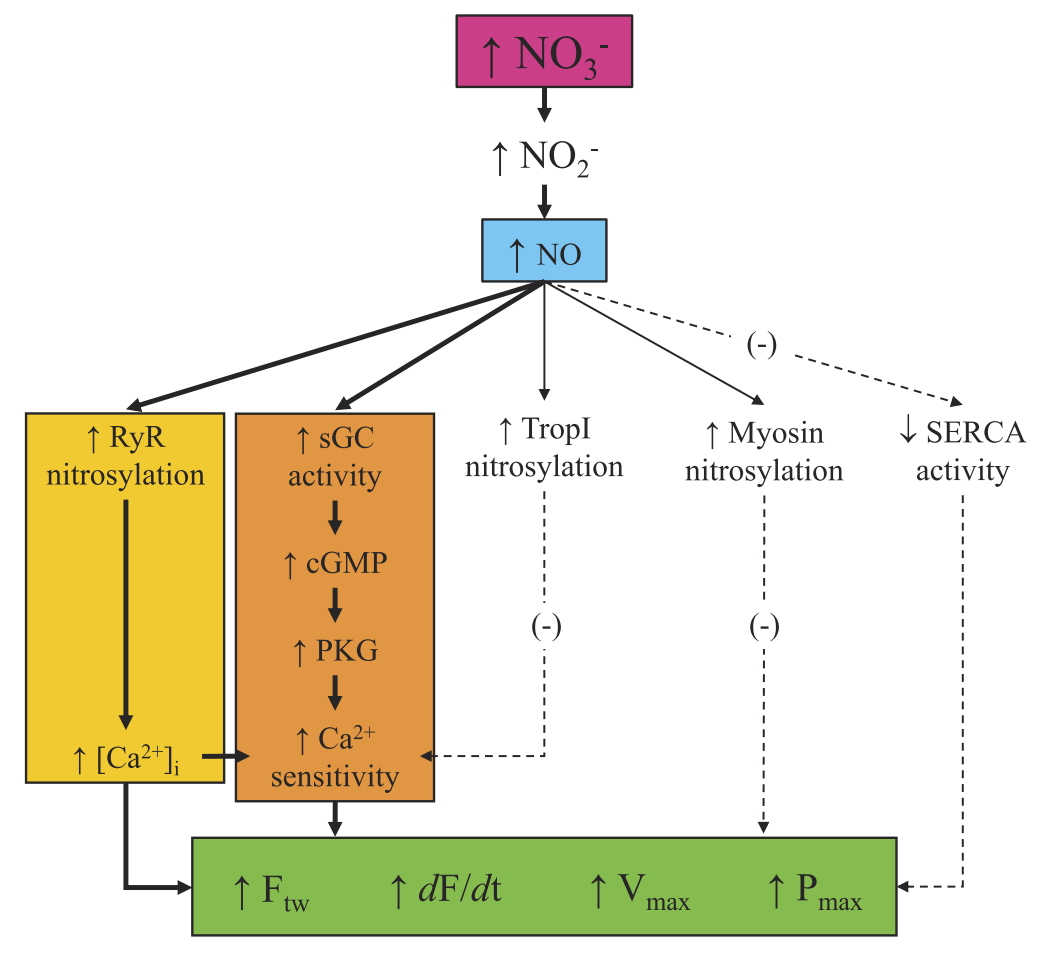

\section{$\uparrow$ Muscle contractile function}

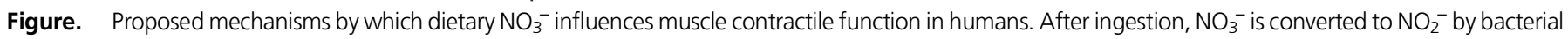
nitroreductases in the oral cavity and endogenous nitroreductases (e.g., xanthine oxidoreductase) in muscle itself. This increase in $\mathrm{NO}_{2}^{-}$in turn leads to enhanced production of the free radical NO. Elevated NO bioavailability then results in multiple effects, as shown in the figure. These include nitrosylation of the sarcroendoplasmic reticululm RyR, which increases $\mathrm{Ca}^{2+}$ release by "locking" this channel in the open configuration. The subsequent increase in free intracellular $\left[\mathrm{Ca}^{2+}\right]_{i}$ contributes to the improvements in twitch force $\left(\mathrm{F}_{\mathrm{tw}}\right)$, rate of force development $(\mathrm{dF} / \mathrm{dt})$, estimated maximal shortening velocity $\left(\mathrm{V}_{\mathrm{max}}\right)$, and maximal power $\left(\mathrm{P}_{\text {max }}\right)$ of muscle that have been observed after dietary $\mathrm{NO}_{3}{ }^{-}$intake. Simultaneously, however, the increase in $\left[\mathrm{Ca}^{2+}\right]_{i}$ also results in activation of skeletal muscle myosin light chain kinase (skMLCK) via the $\mathrm{Ca}^{2+}{ }_{-} \mathrm{CaM}$ pathway and hence an increase in myosin regulatory light chain phosphorylation (pRLC). This results in greater $\mathrm{Ca}^{2+}$ sensitivity of the contractile apparatus, thereby also contributing to the increases in $\mathrm{F}_{\mathrm{tw}}, d \mathrm{~F} / \mathrm{dt}$, $\mathrm{V}_{\max }$, and $\mathrm{P}_{\max }$. Paralleling these events, the increase in NO also results in activation of sGC and hence an increase in CGMP production. This increase in cGMP stimulates PKG activity, which in turn enhances regulatory light chain phosphorylation and hence $\mathrm{Ca}^{2+}$ sensitivity, thus improving muscle contractile function. Finally, also shown are the effects of increased NO on Tropl, on the myosin heavy chain, and on the SERCA. An increase in NO can enhance nitrosylation of Tropl in fast-twitch (but not slow-twitch) fibers, but this inhibits (lines) Ca ${ }^{2+}$ sensitivity, which is the opposite of what has been observed after dietary $\mathrm{NO}_{3}{ }^{-}$supplementation. Similarly, elevation in $\mathrm{NO}$ could increase nitrosylation of myosin, but this would diminish, not enhance, muscle contractile function. Elevated NO also can inhibit SERCA directly, but this would also tend to diminish muscle function, by slowing the rate of relaxation and resulting in eventual depletion of sarcoplasmic reticulum $\mathrm{Ca}^{2+}$ stores. Thus, these other potential effects of $\mathrm{NO}$ cannot explain the dietary $\mathrm{NO}_{3}^{-}$-induced improvements in contractility that have been found repeatedly. $\mathrm{CGMP}$, cyclic guanosine monophosphate; $\mathrm{NO}^{-}$, nitric oxide; $\mathrm{NO}_{2}^{-}$, nitrite; $\mathrm{NO}_{3}{ }^{-}$, nitrate; PKG, protein kinase G; RyR, ryanodine receptor; SERCA, sarcoendoplasmic reticulum Ca ${ }^{2+}$ ATPase; sGC, soluble guanyl cyclase. 
(iNOS, or NOS-2), and endothelial (eNOS, or NOS-3) (24). Although all three types are present in muscle, NOS-1 is considered to be the primary source of $\mathrm{NO}$ in this tissue, and in rodents, is almost exclusively expressed in fast-twitch muscle fibers (24). In humans, however, NOS-1 expression is similar, or even greater, in slow-twitch versus fast-twitch fibers (24). NOS activity increases several-fold during muscle contractions, apparently as a result of $\mathrm{Ca}^{2+}$-dependent activation of NOS-1, and at least in mice is accompanied by a quantitatively-similar increase in cGMP levels in fast-twitch but not slow-twitch muscle (24). This contraction-induced increase in NO production potentially influences numerous aspects of muscle physiology, for example, blood flow, glucose uptake, mitochondrial respiration, etc., via both cGMP-dependent and cGMP-independent pathways (24). These effects are beyond the scope of this review and hence will not be considered further here. Conversely, the effects of $\mathrm{NO}$ muscle contractile properties are directly relevant and in fact have been studied for many years, primarily in isolated animal muscle using pharmacological inhibitors or activators of NOS. In general, these studies have emphasized the possible suppressive effects of $\mathrm{NO}$ on muscle function, especially maximal isometric force (cf. (25) for review). As discussed by Maréchal and Gailly (25), however, this direct "braking" effect seems to be countered a cGMP-mediated enhancement of maximal shortening velocity, which improves contractile function during twitch or isotonic contractions. The specific pathways by which NO modulates skeletal muscle contraction are considered in greater detail under the Mechanisms section.

\section{Dietary $\mathrm{NO}_{3}{ }^{-}$as a Source of $\mathrm{NO}$ in Muscle}

In addition to the NOS pathway, $\mathrm{NO}$ also can be produced via a NOS-independent, "backup" pathway, that is, via reduction of $\mathrm{NO}_{3}^{-}$to $\mathrm{NO}_{2}^{-}$by oral bacteria (1) or endogenous nitroreductases (e.g., xanthine oxidase) (26), followed by further reduction of $\mathrm{NO}_{2}^{-}$to $\mathrm{NO}$ within various tissues. As emphasized by Piknova et al. (26), the latter process would be favored by the low $\mathrm{pH}$ and $\mathrm{O}_{2}$ tension found in resting and especially contracting muscle. Conversely, $\mathrm{NO}_{2}^{-}$and hence $\mathrm{NO}_{3}^{-}$ can be generated via oxidation of L-arginine-derived $\mathrm{NO}$, or, alternatively, obtained from dietary sources. Indeed, numerous studies have demonstrated that acute ingestion of $\mathrm{NO}_{3}^{-}$increases plasma $\mathrm{NO}_{3}^{-}$and $\mathrm{NO}_{2}^{-}$concentrations (e.g., (2,3,10,12-14,16-20)), as well as the levels of $\mathrm{NO}$ in expired breath (frequently used as a biomarker of whole-body $\mathrm{NO}$ production) $(11,14,18,19)$. Until very recently, though, no study had demonstrated directly that dietary $\mathrm{NO}_{3}^{-}$supplementation increases muscle $\mathrm{NO}_{3}^{-}$or $\mathrm{NO}_{2}^{-}$levels in either animals or humans. Working in Schechter's laboratory, however, Gilliard et al. (27) recently reported that feeding rats a high $\mathrm{NO}_{3}{ }^{-}$diet for $7 \mathrm{~d}$ increased $(P<0.05)$ muscle $\mathrm{NO}_{3}^{-}$ and $\mathrm{NO}_{2}^{-}$content by $\sim 33 \%$ and $>100 \%$, respectively. Acute ingestion of $150 \mu \mathrm{mol} \cdot \mathrm{kg}^{-1}(\sim 12.3 \mathrm{mmol})$ of $\mathrm{NO}_{3}^{-}$has also recently been shown to more than triple $(P<0.001)$ the $\mathrm{NO}_{3}^{-}$content of muscle biopsy samples from older men with diabetes (28), although the small size of such samples apparently precluded measurement of $\mathrm{NO}_{2}^{-}$content using the standard chemiluminescent approach. Schechter's group has reported also that strenuous endurance exercise results in a dramatic reduction in muscle $\mathrm{NO}_{3}^{-}$and $\mathrm{NO}_{2}^{-}$levels in rats, which in the absence of $\mathrm{NO}_{3}^{-}$intake remain suppressed for at least $12 \mathrm{~h}$ (26). Taken together, these data indicate that muscle $\mathrm{NO}_{3}^{-}$and $\mathrm{NO}_{2}^{-}$are both highly responsive to, and highly dependent upon, dietary intake. The effects of dietary $\mathrm{NO}_{3}^{-}$on muscle contractile function as discussed as follows are presumably the result of increased NO production via this NOSindependent pathway. However, the precise mechanism by which dietary $\mathrm{NO}_{3}^{-}$might alter human muscle contractile properties is still unknown, and direct effects of $\mathrm{NO}_{2}^{-}$and other reactive nitrogen species (e.g., peroxynitrite) cannot be ruled out completely.

\section{Dietary $\mathrm{NO}_{3}{ }^{-}$and Muscle Contractile Function}

In 2012, Hernández et al. (22) demonstrated that, in mice, $7 \mathrm{~d}$ of $\left(\mathrm{NO}_{3}^{-}\right)$supplementation markedly increased the force generated by fast-twitch, but not slow-twitch, muscle during lower frequency electrical stimulation. There were, though, no changes at higher frequencies of stimulation, that is, in tetanic force, or in the rate of force development. The results of this study will be considered in greater detail later. The first $h u$ man study to touch upon the question at hand, however, was that of Fulford et al. (29), who in 2013 determined the effects of ingesting $10.2 \mathrm{mmol}$ of $\mathrm{NO}_{3}^{-}$either acutely or daily for 5-15 d, including on the day of testing, during isometric knee extensor exercise in healthy, untrained young men (Table). This reduced the energetic cost of exercise, as determined using ${ }^{31} \mathrm{P}$ magnetic resonance spectroscopy, but maximal voluntary force production was unchanged. No other measurements of muscle function were obtained, however, nor was there any evidence of any chronic effects of $\mathrm{NO}_{3}{ }^{-}$supplementation on muscle energetics (i.e., similar results were obtained during all three trials). The latter finding is consistent with the apparent absence of any chronic effects of dietary $\mathrm{NO}_{3}^{-}$supplementation on human muscle contractile properties, as will be discussed.

Haider and Folland (10) in 2014 were the first to extensively assess the impact of dietary $\mathrm{NO}_{3}{ }^{-}$on human muscle contractility, by determining the effects of ingesting $9.7 \mathrm{mmol}$ of $\mathrm{NO}_{3}{ }^{-} / \mathrm{d}$ for $7 \mathrm{~d}$, including on the day of testing, on voluntary and electrically stimulated isometric knee extension exercise in healthy, untrained young men. Although no differences were observed during voluntary exercise, small (i.e., 3\%-15\%), but statistically significant (i.e., $P<0.01-0.05$ ), improvements in twitch force, force at $10 \mathrm{~Hz}$, and force during the first $50 \mathrm{~ms}$ of contraction were found during transcutaneous electrical stimulation. Similar, but slightly larger, improvements $(P<0.01-0.05)$ have since been reported by Whitfield et al. (12) in healthy, untrained young men ingesting $26 \mathrm{mmol}$ of $\mathrm{NO}_{3}^{-} / \mathrm{d}$ for $7 \mathrm{~d}$ (including on the day of testing).

The data of Haider and Folland (10) and later Whitfield et al. (12) clearly demonstrate that ingestion of $\mathrm{NO}_{3}{ }^{-}$can alter human muscle contractile function, at least during electrically stimulated isometric exercise. In contrast, using very similar methods, Hoon et al. (30) found no changes in maximal voluntary force or in twitch force, the rate of force development, the rate of relaxation, or in force at $10-100 \mathrm{~Hz}$ of electrical stimulation after $3 \mathrm{~d}$ of $\mathrm{NO}_{3}^{-}$supplementation at (ostensibly) $8.8 \mathrm{mmol} \cdot \mathrm{d}^{-1}$ plus $17.6 \mathrm{mmol}$ on the day of testing. $\left(\mathrm{NO}_{3}{ }^{-}\right.$supplementation did attenuate the rate of fatigue development during repetitive stimulation for $\geq 80 \mathrm{~s}$, but only when blood flow was restricted.) Although it might be tempting to speculate that these largely negative results are due to the shorter supplementation period, this seems unlikely given that improvements in muscle function have been observed even after an acute dose of $\mathrm{NO}_{3}{ }^{-}$(see as follows). The reasons why Hoon et al. (30) did not find any 
TABLE. Studies of the effects of dietary $\mathrm{NO}_{3}-$ on human muscle contractile properties

\begin{tabular}{|c|c|c|c|c|}
\hline Reference & Subjects & Exercise Mode & Dose & Relevant Findings \\
\hline Fulford et al. 2013 (29) & Healthy young men $(\mathrm{n}=8)$ & $\begin{array}{l}\text { Isometric knee } \\
\text { extension (voluntary) }\end{array}$ & $\begin{array}{l}10.2 \text { mmol } \mathrm{NO}_{3}-2.5 \mathrm{~h} \\
\text { before testing or daily for } \\
5 \text { or } 15 \mathrm{~d} \text { including } 2.5 \mathrm{~h} \\
\text { before testing }\end{array}$ & $\leftrightarrow \mathrm{MVF}$ \\
\hline Haider and Folland, 2014 (10) & Healthy young men $(n=19)$ & $\begin{array}{l}\text { Isometric knee extension } \\
\text { (voluntary and } \\
\text { electrically stimulated) }\end{array}$ & $\begin{array}{l}9.7 \text { mmol } \mathrm{NO}_{3}-/ \mathrm{d} \text { for } 7 \mathrm{~d} \\
\text { including } 2.5 \mathrm{~h} \text { before testing }\end{array}$ & $\begin{array}{l}\leftrightarrow \mathrm{MVF}, \leftrightarrow d \mathrm{~F} / d \mathrm{t} \text {, during voluntary exercise } \\
\uparrow \mathrm{F}_{\mathrm{tw}}, \uparrow \mathrm{F} @ 1-20 \mathrm{~Hz}, \uparrow d \mathrm{~F} / d \mathrm{t} \text { during } \\
\quad \text { electrical simulation }\end{array}$ \\
\hline Coggan et al., 2015 (11) & $\begin{array}{l}\text { Healthy young and middle-aged } \\
\text { men and women }(n=12)\end{array}$ & $\begin{array}{l}\text { Isometric and isokinetic } \\
\text { knee extension (voluntary) }\end{array}$ & $\begin{array}{l}11.2 \text { mmol } \mathrm{NO}_{3}-2.5 \mathrm{~h} \\
\text { before testing }\end{array}$ & $\begin{aligned} \leftrightarrow & \mathrm{MVF}, \leftrightarrow \mathrm{F} \text { at } 1.67,3.14, \text { and } \\
& 4.71 \mathrm{rad} \cdot \mathrm{s}-1, \uparrow \mathrm{F} \text { at } 6.28 \mathrm{rad} \cdot \mathrm{s}-1 \\
& \uparrow \mathrm{Pmax}, \uparrow \mathrm{Vmax}\end{aligned}$ \\
\hline Coggan et al., 2015 (18) & $\begin{array}{l}\text { Middle-aged patients with } \\
\qquad \mathrm{HF}(\mathrm{n}=9)\end{array}$ & $\begin{array}{l}\text { Isometric and isokinetic } \\
\text { knee extension (voluntary) }\end{array}$ & $11.2 \mathrm{mmol} \mathrm{NO}_{3}-2.5 \mathrm{~h}$ before testing & $\begin{aligned} \leftrightarrow & M V F, \leftrightarrow F \text { at } 1.67 \text { and } 3.14 \mathrm{rad} \cdot \mathrm{s}-1, \\
& \uparrow \mathrm{F} \text { at } 4.71 \text { and } 6.28 \mathrm{rad} \cdot \mathrm{s}-1, \\
& \uparrow \mathrm{Pmax}, \uparrow V_{\max }\end{aligned}$ \\
\hline Hoon et al., 2015 (30) & $\begin{array}{l}\text { Healthy young men and } \\
\text { women }(\mathrm{n}=18)\end{array}$ & $\begin{array}{l}\text { Isometric knee extension } \\
\text { (voluntary and } \\
\text { electrically stimulated) }\end{array}$ & $\begin{array}{l}8.8 \mathrm{mmol} \mathrm{NO}-/ \mathrm{d} \text { for } 3 \mathrm{~d} \text { plus } \\
\quad 17.6 \mathrm{mmol} \mathrm{NO}_{3}-2-4 \mathrm{~h} \text { before testing }\end{array}$ & $\begin{aligned} \leftrightarrow & \text { MVF during voluntary exercise } \\
\leftrightarrow & d \mathrm{~F} / d \mathrm{t}, \leftrightarrow \mathrm{F}_{\mathrm{tw}}, \leftrightarrow-d \mathrm{~F} / \mathrm{dt}, \leftrightarrow \mathrm{F} @ 10-100 \mathrm{~Hz} \\
& \text { during electrical stimulation }\end{aligned}$ \\
\hline Rimer et al. 2016 (15) & $\begin{array}{l}\text { Collegiate team sport and } \\
\text { endurance athletes }(n=13)\end{array}$ & $\begin{array}{l}\text { Inertial load and isokinetic } \\
\text { cycling (voluntary) }\end{array}$ & $11.2 \mathrm{mmol} \mathrm{NO}_{3}-2.5 \mathrm{~h}$ before testing & $\uparrow \operatorname{Pmax}, \uparrow$ RPMopt \\
\hline Kramer et al. 2016 (16) & Male CrossFit athletes $(n=12)$ & $\begin{array}{l}\text { Isometric and isokinetic } \\
\text { knee extension and } \\
\text { flexion (voluntary) } \\
\text { Wingate test (voluntary) }\end{array}$ & $\begin{array}{l}8 \mathrm{mmol} \mathrm{NO}-/ \mathrm{d} \text { for } 6 \mathrm{~d} \text { with } \\
\quad \text { last dose } \geq 24 \mathrm{~h} \text { before testing }\end{array}$ & $\begin{array}{l}\leftrightarrow \mathrm{MVF}, \leftrightarrow \mathrm{F} \text { at } 1.05 \text { and } 3.14 \mathrm{rad} \cdot \mathrm{s}-1 \\
\text { during isokinetic exercise } \\
\uparrow \text { Wpeak during cycling }\end{array}$ \\
\hline Coggan et al., 2017 (19) & $\begin{array}{l}\text { Healthy older men } \\
\text { and women }(n=6)\end{array}$ & $\begin{array}{l}\text { Isometric and isokinetic } \\
\text { knee extension (voluntary) }\end{array}$ & $\begin{array}{l}11.2 \text { mmol } \mathrm{NO}_{3}-2.5 \mathrm{~h} \\
\text { before testing }\end{array}$ & $\begin{aligned} \leftrightarrow & M V F, \leftrightarrow F \text { at } 1.67,3.14 \text { and } 4.71 \\
& \operatorname{rad} \cdot s-1, \uparrow F \text { at } 6.28 \mathrm{rad} \cdot s-1(4 \text { of } 6), \\
& \uparrow P \max (4 \text { of } 6), \uparrow V \max (5 \text { of } 6)\end{aligned}$ \\
\hline Whitfield et al., 2017 (12) & Healthy young men $(\mathrm{n}=8)$ & $\begin{array}{l}\text { Isometric knee extension } \\
\text { (voluntary and } \\
\text { electrically stimulated) }\end{array}$ & $\begin{array}{l}26 \mathrm{mmol} \mathrm{NO}_{3}-/ \mathrm{d} \text { for } 7 \mathrm{~d} \text { including } \\
1.5 \mathrm{~h} \text { before testing }\end{array}$ & $\begin{aligned} \leftrightarrow & \text { MVF during voluntary exercise } \uparrow \mathrm{F}_{\mathrm{tw}} \\
& \uparrow \mathrm{F} @ 10 \mathrm{~Hz}, \uparrow d \mathrm{~F} / d \mathrm{t}, \uparrow-d \mathrm{~F} / \mathrm{dt} \\
& \text { during electrical stimulation }\end{aligned}$ \\
\hline Domínguez et al., 2018 (13) & Healthy young men $(n=15)$ & Wingate test (voluntary) & $5.6 \mathrm{mmol} \mathrm{NO} \mathrm{N}_{3}-3 \mathrm{~h}$ before testing & $\uparrow$ Wpeak, $\downarrow$ time to Wpeak \\
\hline Coggan et al., 2018 (14) & $\begin{array}{l}\text { Healthy men and women } \\
\quad(n=20, \text { including data } \\
\text { from } n=12 \text { in Ref. } 9)\end{array}$ & $\begin{array}{l}\text { Isometric and isokinetic } \\
\text { knee extension (voluntary) }\end{array}$ & $11.2 \mathrm{mmol} \mathrm{NO}_{3}-2.5 \mathrm{~h}$ before testing & $\uparrow P \max , \uparrow V \max$ \\
\hline Jonvik et al., 2018 (17) & $\begin{array}{l}\text { Recreational }(\mathrm{n}=10), \text { competitive } \\
\quad(\mathrm{n}=22), \text { and elite }(\mathrm{n}=10) \\
\text { male and female athletes }\end{array}$ & $\begin{array}{l}\text { Repeated }(\mathrm{n}=3) \\
\text { Wingate tests } \\
\text { (voluntary) }\end{array}$ & $\begin{array}{l}12.9 \mathrm{mmol} \cdot \mathrm{d}-1 \text { for } 6 \mathrm{~d} \text { including } \\
3 \mathrm{~h} \text { before testing }\end{array}$ & $\leftrightarrow$ Wpeak, $\downarrow$ time to Wpeak \\
\hline
\end{tabular}

$\leftrightarrow$, unchanged; $\uparrow$, significantly increased; $\downarrow$, significantly decreased; $d F / d t$, rate of force development; $-d F / d t$, rate of relaxation; $F_{t w}$, twitch force; $F$, force; $M V F$, maximal voluntary force; $N O_{3}$

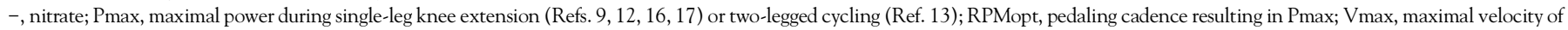
knee extension; Wpeak, peak power during two-legged cycling.

changes in unfatigued muscle are unclear, although it is worth noting that these investigators used a BRJ product of unverified $\mathrm{NO}_{3}{ }^{-}$content and did not measure any markers of $\mathrm{NO}$ bioavailability (e.g., plasma $\mathrm{NO}_{2}{ }^{-}$, breath $\mathrm{NO}$ ).

Given the data previously discussed, it is natural to wonder whether dietary $\mathrm{NO}_{3}{ }^{-}$can influence human muscle function during voluntary, dynamic exercise. Indeed, contemporaneous with Haider and Folland's (10) research, we used isokinetic dynamometry to address this question in healthy, young and middle-aged men and women (11). We found that a single dose of $11.2 \mathrm{mmol}$ of $\mathrm{NO}_{3}{ }^{-} 2-3 \mathrm{~h}$ before testing did not increase maximal isometric force or the force (torque) generated at slower velocities of knee extension. Acute $\mathrm{NO}_{3}{ }^{-}$ingestion did, however, enhance force at higher velocities, resulting in $11 \%$ and $6 \%$ increases (both $P<0.05$ ) in calculated maximal speed $\left(V_{\max }\right)$ and power $(\mathrm{Pmax})$, respectively. Subsequently, we found even greater improvements in Vmax and $P \max$ (i.e., of $12 \%$ and 13\%, respectively; both $P<0.05)$ in response to the same dose of $\mathrm{NO}_{3}{ }^{-}$in middle-aged patients with $\mathrm{HF}$ (18), presumably because such patients are NO deficient $(31,32)$. Because NO bioavailability also decreases with age (33), we have since examined the effects of acute $\mathrm{NO}_{3}{ }^{-}$ingestion on the $\mathrm{Vmax}$ and Pmax of the knee extensors of healthy, elderly subjects (19). Although preliminary in nature, the data from this study indicate that older subjects also demonstrate improvements in $\mathrm{Vmax}$ and Pmax, at least provided that the dose of $\mathrm{NO}_{3}{ }^{-}$ ingested is $>125 \mu \mathrm{mol} \cdot \mathrm{kg}^{-1}$. The conclusion that $\mathrm{NO}_{3}{ }^{-}$ingestion can improve contractile function even in aged muscle is supported by the findings of Justice et al. (20), who found that daily supplementation with $\mathrm{NO}_{2}^{-}$for 10 wk increased $(P<0.01)$ the rate of force development during voluntary knee extension and flexion in healthy, middle-aged and older men and women. Finally, we have expanded recently upon our original study (11) to investigate determinants of interindividual differences in the effects of dietary $\mathrm{NO}_{2}{ }^{-}$on muscle function in a larger cohort (14). As before, we observed significant increases in Vmax and Pmax (both $\mathrm{P}<0.05$ ) in response to $\mathrm{NO}_{3}{ }^{-}$intake, with the size of these improvements being positively associated with the magnitude of the increase in plasma $\mathrm{NO}_{2}{ }^{-}$concentration $(P<0.01)$ and possibly female sex $(P<0.08)$, but not with other parameters, including baseline $V \max$ or decline in force during a 50 contraction fatigue test (in vivo indicators of muscle fiber type distribution).

All of the data described previously were obtained during isolated contractions performed by a single muscle/muscle group acting across a single joint. To determine whether dietary $\mathrm{NO}_{3}^{-}$also improves contractile performance during repeated multi-muscle, multi-joint movements, we collaborated with 
Dr. Jim Martin and Ernie Rimer at the University of Utah to determine the effects of acute supplementation with $11.2 \mathrm{mmol}$ of $\mathrm{NO}_{3}^{-}$on performance during inertial load sprint cycling (15). Similar to our isokinetic dynamometry results, we found that $\mathrm{NO}_{3}{ }^{-}$intake increased $(P<0.05)$ both cycling Pmax and the associated pedaling rate by $6 \%$ in a heterogeneous group of endurance and collegiate team sport athletes. These results have since essentially been confirmed by Domínguez et al. (13), who found that ingestion of $5.6 \mathrm{mmol}$ of $\mathrm{NO}_{3}^{-} 3 \mathrm{~h}$ before a Wingate cycling test increased $(P<0.05)$ peak power by $6 \%$. Time-to-peak power also tended to be reduced $(P=0.06)$. Jonvik et al. (17) also recently reported that ingestion of $12.9 \mathrm{mmol}$ of $\mathrm{NO}_{3}{ }^{-} / \mathrm{d}$ for 6 (including $3 \mathrm{~h}$ before testing) significantly (i.e., $\mathrm{P}<0.01$ ) reduced time-to-peak power (by $3 \%$ ) during Wingate testing of speed skaters, although peak power itself was unchanged.

Along the same lines, Kramer et al. (16) recently found that ingesting $8 \mathrm{mmol}$ of $\mathrm{NO}_{3}^{-} / \mathrm{d}$ for $6 \mathrm{~d}$ improved the peak power of male CrossFit athletes during a Wingate test by $7 \%(P<0.01)$, even though it did not alter force during isometric or isokinetic knee extension or flexion at slow velocities. Unlike in other studies, however, subjects were tested $\geq 24 \mathrm{~h}$ after the last dose of $\mathrm{NO}_{3}{ }^{-}$, after which plasma $\mathrm{NO}_{3}{ }^{-}$and $\mathrm{NO}_{2}{ }^{-}$levels would be expected to have returned to near normal. Nonetheless, it seems unlikely that the results of Kramer et al. (16) represent any sort of long-term structural adaptation, because similar improvements have been observed after just a single dose of $\mathrm{NO}_{3}^{-}(13,15)$. Furthermore, recent data from Whitfield et al. (12) demonstrate that, unlike in mice (22), $\mathrm{NO}_{3}{ }^{-}$supplementation of humans does not alter the expression of key $\mathrm{Ca}^{2+}$ handling proteins in muscle (see Mechanisms). Thus, the results of Kramer et al. (16) are presumably simply the result of a "loading" effect of previous $\mathrm{NO}_{3}^{-}$ intake on intramuscular $\mathrm{NO}_{3}{ }^{-}$and $\mathrm{NO}_{2}{ }^{-}$stores, versus any more permanent adaptations in muscle.

Finally, several recent studies of male team sport athletes by Jones et al. (34-36) also provide indirect evidence that dietary $\mathrm{NO}_{3}{ }^{-}$can enhance the contractile properties of human muscle. In the first (34), ingestion of $12.8 \mathrm{mmol}$ of $\mathrm{NO}_{3}^{-} / \mathrm{d}$ for $7 \mathrm{~d}$ (including $2.5 \mathrm{~h}$ before testing) was shown to improve (i.e., $P<0.05)$ performance during the early phases of an intermittent sprint cycling protocol designed to mimic the demands of, for example, international field hockey. Similar results were obtained by Wylie et al. (35) in subjects ingesting $8.2 \mathrm{mmol}$ of $\mathrm{NO}_{3}{ }^{-} / \mathrm{d}$ for $5 \mathrm{~d}$ (including $2.5 \mathrm{~h}$ before testing) and performing repeated $6 \mathrm{~s}$ (but not 30 or $60 \mathrm{~s}$ ) all-out efforts. Finally, in another study (35), supplementation with $6.4 \mathrm{mmol}$ of $\mathrm{NO}_{3}^{-} / \mathrm{d}$ for $5 \mathrm{~d}$ (including 2.5 before testing) was found to improve significantly (i.e., $P<0.05$ ) $0-5$ and 5-10, but not $10-20$, $\mathrm{m}$ split times during an intermittent sprint running test. Although somewhat indirect, the results of these studies are consistent with the dietary $\mathrm{NO}_{3}{ }^{-}$-induced increases in muscle contractility found both by ourselves $(11,14,15,18,19)$ and others $(10,12,13,16,17,20)$.

In summary, numerous recent studies have demonstrated that ingestion of $\mathrm{NO}_{3}{ }^{-}$significantly enhances muscle contractile function in humans. This effect seems to be the result of an increase in the number of active actomyosin cross-bridges and in the rate of cross-bridge cycling under load, and not an increase in the force generated per active cross-bridge. This interpretation is based upon the improvements observed in isometric twitch force $(10,12)$, rate of isometric force development $(10,12,20)$, isometric force during low-frequency electrical stimulation $(10,12)$, isokinetic/dynamic force and power during high-velocity muscle shortening $(11,13-17)$, and increased estimated maximal speed of shortening $(11,15,19)$, all in the absence of any significant improvement in the force-generating capacity of muscle during maximal voluntary contractions $(10-12,14,16,19,20,30)$ or at higher frequencies of electrical stimulation $(10,12)$. The specific biochemical mechanisms by which dietary $\mathrm{NO}_{3}{ }^{-}$might alter the contractile characteristics of human muscle are considered in greater detail as follows.

\section{Mechanisms}

As mentioned previously, using mice, Hernández et al. (22) were the first to determine the effects of dietary $\mathrm{NO}_{3}{ }^{-}$on muscle contractility. Along with the fast twitch fiber-specific changes in function described previously, these authors found that $\mathrm{NO}_{3}{ }^{-}$supplementation increased $\left[\mathrm{Ca}^{2+}\right]_{\mathrm{i}}$ in muscle, both at rest and during tetanic contractions, and also shifted the force- $\mathrm{Ca}^{2+}$ relation, resulting in increased force at moderately high, but sub-saturating, $\mathrm{Ca}^{2+}$ levels. These effects were ascribed to increased expression of the $\mathrm{Ca}^{2+}$-handling proteins calsequestrin (CSQ) and the dihydropyridine (DHPR) receptor. More recently, however, Whitfield et al. (12) found that $\mathrm{NO}_{3}{ }^{-}$supplementation did not alter the expression of CSQ, DHPR, or other $\mathrm{Ca}^{2+}$-handling proteins, that is, $\mathrm{RyR}$ or the sarcoendoplasmic reticulum $\mathrm{Ca}^{2+}$ ATPase (SERCA), in human muscle. Furthermore, changes in protein expression cannot explain the improvements in muscle contractile function that we $(11,14,15,18,19)$ and others (13) have observed repeatedly after acute $\mathrm{NO}_{3}{ }^{-}$ingestion, nor could the changes in CSQ and DHPR reported by Hernández et al. (22) seemingly explain the altered $\mathrm{Ca}^{2+}$ sensitivity that these authors also found.

In the absence of changes in protein expression, Whitfield et al. (12) speculated that $\mathrm{NO}_{3}{ }^{-}$-induced improvements in muscle function may be due to enhanced production of reactive $\mathrm{O}_{2}$ species. This hypothesis was based on the observations of Andrade et al. (37), who reported that $\mathrm{H}_{2} \mathrm{O}_{2}$ reduces $\mathrm{Ca}^{2+}$ release but increases maximal tetanic force in isolated mouse muscle fibers. However, Whitfield et al. (12) found no changes in the levels of protein carbonylation or lipid peroxidation or in the ratio of reduced to oxidized glutathione, which would argue against significant changes in cellular redox status. More importantly, dietary $\mathrm{NO}_{3}{ }^{-}$actually increases $\mathrm{Ca}^{2+}$ release in mice (22) and has failed routinely to increase either maximal voluntary or maximal electrically stimulated force in numerous human studies $((10-12,16,18,19,30)$; Table), effects that are precisely the opposite of those due to $\mathrm{H}_{2} \mathrm{O}_{2}$ (37). Increased production of reactive $\mathrm{O}_{2}$ species also cannot account for the improvements in muscle contractility that result from $\mathrm{NO}_{3}^{-}$intake.

Given that neither changes in protein expression nor in redox state can seemingly explain dietary $\mathrm{NO}_{3}{ }^{-}$-induced improvements in human muscle contractile function, what mechanism(s) is (are) responsible? Historically, NO was considered to act exclusively via the sGC-cGMP-PKG pathway (38). In the last few decades, however, it has become increasingly recognized that $\mathrm{NO}$ also can influence cellular events more directly, either by itself or after nitrosylation or transnitrosylation of thiols, especially cysteine residues of proteins (39). In skeletal muscle, however, most non-cGMP-mediated effects of NO 
are actually inhibitory, that is, they tend to diminish, not enhance, muscle contractile function. For example, it has been shown that NO directly inhibits the activity of SERCA in rabbit fast twitch muscle (40). This would be expected to slow the rate of relaxation and limit the amount of $\mathrm{Ca}^{2+}$ released (and hence force generated) during subsequent contractions, due to depletion of $\mathrm{Ca}^{2+}$ from the sarcoplasmic reticulum. Somewhat along the same lines, high-intensity exercise has been found to stimulate transnitrosylation of myosin in rat fast twitch muscle (41), but this inhibited the $\mathrm{Mg}^{2+}$ ATPase activity of the protein. All else being equal, this would reduce maximal shortening velocity. Increased NO availability may lead also to reversible transnitrosylation of troponin I (TropI) (42), but the consequence of this is a reduction in $\mathrm{Ca}^{2+}$ sensitivity of rat and human fast-twitch and no change in slow-twitch fibers. All of these effects (i.e., decline in $\mathrm{Ca}^{2+}$ release, decrease in speed of shortening, reduction or no change in $\mathrm{Ca}^{2+}$ sensitivity) are the opposite of those that have been observed after dietary $\mathrm{NO}_{3}{ }^{-}$supplementation.

In contrast to the inhibitory effects described previously, transnitrosylation of $\mathrm{R}_{\mathrm{y}} \mathrm{R}$ may be one mechanism by which $\mathrm{NO}$ could enhance muscle contractile function. This posttranslational modification of the protein enhances $\mathrm{Ca}^{2+}$ release (43), by increasing the probability of the channel being in the open state (44). In particular, at low $\mathrm{O}_{2}$ tensions typical of skeletal muscle in vivo even submicromolar concentrations of $\mathrm{NO}$ will activate type $1 \mathrm{RyRs}$ (45), as a result of transnitrosylation of a single cysteine residue (46). This blocks the inhibitory effects of calmodulin $(\mathrm{CaM})$ on RyR1, thereby enhancing $\mathrm{Ca}^{2+}$ release and force production. Thus, although excessive nitrosylation of RyRs and hence sustained elevations in $\left[\mathrm{Ca}^{2+}\right]_{\mathrm{i}}$ in muscle are thought to play a key role in exertional heatstroke and malignant hyperthermia (47), physiological (rather than pathophysiological) increases in $\mathrm{NO}$ and hence in $\mathrm{RyR}$ nitrosylation and $\mathrm{Ca}^{2+}$ release as a result of dietary $\mathrm{NO}_{3}^{-}$intake could be responsible for the accompanying improvements in muscle contractile function. Specifically, under sub-saturating conditions dietary $\mathrm{NO}_{3}{ }^{-}$-induced increases in $\left[\mathrm{Ca}^{2+}\right]_{\mathrm{i}}(22)$ would enhance twitch force, rate of force development, shortening velocity, and power, whereas no changes would be expected to occur under saturating conditions, for example, during a sustained maximal isometric contraction. These functional changes are, of course, precisely those that have been observed in response to acute and chronic $\mathrm{NO}_{3}^{-}$supplementation. An increase in $\left[\mathrm{Ca}^{2+}\right]_{\mathrm{i}}$ during contractions due to RyR nitrosylation could explain also the increase in $\mathrm{Ca}^{2+}$ sensitivity observed by Hernández et al. (22), by enhancing myosin regulatory light chain phosphorylation (pRLC) via the $\mathrm{Ca}^{2+}$. CaM-skeletal muscle myosin light chain kinase (skMLCK) pathway (23). Indeed, the effects of dietary $\mathrm{NO}_{3}^{-}$on muscle contractile properties are essentially identical to those resulting from increased pRLC (23). Together, these two effects (i.e., an increase in $\left[\mathrm{Ca}^{2+}\right]_{\mathrm{i}}$ and in $\mathrm{Ca}^{2+}$ sensitivity, both as a result of RyR nitrosylation) could account for all of the changes in muscle contractile properties that have been observed in response to dietary $\mathrm{NO}_{3}^{-}$intake.

Alternatively and in addition, enhanced NO signaling via the original sGC-cGMP-PKG pathway is another possible mechanism by which $\mathrm{NO}_{3}{ }^{-}$supplementation improves muscle contractile function in humans. In this scenario, which is based on that originally hypothesized by Maréchal and Beckers-Bleukx (48), an increase in $\mathrm{NO}$ bioavailability resulting from dietary $\mathrm{NO}_{3}^{-}$intake results in activation of sGC, and hence an increase in cGMP production. Increased cGMP levels in turn result in activation of PKG and hence in skMLCK activity, leading to an increase in pRLC. This would enhance $\mathrm{Ca}^{2+}$ sensitivity of the contractile apparatus, thereby accounting for all of the functional changes mentioned previously. (An increase in skMLCK activity would not explain the increase in $\mathrm{Ca}^{2+}$ release reported by Hernández et al. (22), as the SR is not a target of this enzyme.) In support of this hypothesis, Maréchal and Beckers-Bleukx (48) demonstrated that sGC inhibitors or activators respectively diminished or augmented the maximal shortening velocity of mouse muscle without altering maximal isometric force, effects that resemble those of dietary $\mathrm{NO}_{3}^{-}$. Maréchal and BeckersBleukx (48) also found that inhibition of NOS reduced basal cGMP levels by $12 \%-27 \%$, whereas others have reported (in abstract) that NOS inhibition reduces pRLC by a similar amount in $\mathrm{C} 2 \mathrm{C} 12$ myotubes (49). Thus, although it remains to be demonstrated that an increase in $\mathrm{NO}$ bioavailability as a result of dietary $\mathrm{NO}_{3}^{-}$intake results in an increase in either cGMP or in pRLC in either animal or human muscle, this alternative or parallel mechanism may also be operative.

\section{Effects of Muscle Fiber Type}

As indicated previously, studies of rodents have demonstrated that the effects of dietary $\mathrm{NO}_{3}{ }^{-}$on contractile properties are specific to fast-twitch muscle (22). In rats, however, muscle contraction results in an increase in pRLC only in fast-twitch fibers, whereas in humans this occurs in both fast-twitch and slowtwitch fibers (23). Furthermore, human (and rat) fast- and slow-twitch muscle fibers primarily or even exclusively express the same isoform of RyR, that is, RyR1 (50). Thus, based on the mechanisms described previously, there would be no reason to hypothesize a fiber type-specific effect of dietary $\mathrm{NO}_{3}^{-}$on the contractile properties of human muscle, even though one exists in rats. In fact, as previously mentioned, we were recently unable to detect any relation between in vivo indicators in muscle fiber type distribution and the magnitude of the dietary $\mathrm{NO}_{3}{ }^{-}$-inducted increase in $\mathrm{Pmax}$ (14). Muscle fiber type distribution was not determined directly in this study, however, so at least at present a fiber type-specific benefit of dietary $\mathrm{NO}_{3}^{-}$supplementation on human muscle function cannot be ruled out completely.

\section{Significance}

Additional research is required to test the previous hypotheses and may prove to be particularly challenging given the previously mentioned differences between humans and rodents, including in the acute responses (21) and chronic adaptations (i.e., (12) vs (22)) to dietary $\mathrm{NO}_{3}^{-}$supplementation. The "crosstalk" between the proposed RyR and sGC-cGMP-PKG pathways (at the level of pRLC) may also make it difficult to determine the relative importance of nitrosylation versus canonical $\mathrm{NO}$ signaling, as is true in other situations. Regardless of the precise mechanism(s) involved, however, the improvements in human muscle contractile function resulting from $\mathrm{NO}_{3}^{-}$ingestion are potentially significant. This is true in the contexts of both sports and general health and well-being. For example, as previously discussed (11), even a $1 \%$ improvement in performance would double the probability of an elite athlete winning a particular competition. Comparatively speaking, the 4\%-13\% 
increase in maximal neuromuscular power resulting from dietary $\mathrm{NO}_{3}{ }^{-}$intake $(11,13-16,18,30)$ is enormous. More importantly, muscle power plays a key role in activities of daily living yet is compromised markedly in, for example, patients with HF due to systolic dysfunction (31). Indeed, reduced muscle contractile function strongly contributes to the whole-body exercise intolerance that is characteristic of the latter "cardiomuscular" disease, and in fact is a powerful predictor of survival in those with HF (31). In this context, as previously discussed (31), the magnitude of the dietary $\mathrm{NO}_{3}^{-}$-induced increase in maximal neuromuscular power we have found in HF patients (18) is sufficient to have acutely erased approximately one third of their expected deficit in this parameter. It is also similar to that resulting from 2 to 3 months of resistance exercise training in such individuals, which has been shown to result in improvement in Minnesota Living with Heart Failure Questionnaire Scores (18). Thus, significant improvements in skeletal muscle contractility due to $\mathrm{NO}_{3}{ }^{-}$ingestion could have a positive impact on quality of life and possibly even lifespan in patients with HF, as well as other subject groups.

\section{Summary}

Numerous recent studies, both by ourselves $(11,14,15,18,19)$ and by others $(10,12,13,16,17,20)$, have demonstrated that acute or chronic $\mathrm{NO}_{3}^{-}$(or $\mathrm{NO}_{2}^{-}(20)$ ) ingestion significantly enhances the contractile properties of human skeletal muscle, especially speed and hence power. Such improvements have been observed in a wide range of subjects, including younger, untrained individuals (10-12,14), trained athletes $(13,15-17)$, patients with HF (18), and the elderly $(19,20)$. The precise mechanisms responsible for this $\mathrm{NO}_{3}{ }^{-}$-induced increase in human muscle contractility are still unknown, but changes in $\mathrm{Ca}^{2+}$ signaling due to increased $\mathrm{NO}$ bioavailability are likely to play a role. Additional research will be needed to test this hypothesis and to determine the practical and clinical benefits of using $\mathrm{NO}_{3}{ }^{-}$supplementation to augment muscle function in healthy and diseased populations.

\section{Acknowledgments}

This study was supported by award no. R34HL138253 from the National Heart, Lung, and Blood Institute (NHLBI) of the National Institutes of Health (NIH). Its contents are solely the responsibility of the authors and do not necessarily represent the official views of the NHLBI or NIH.

\section{References}

1. Lundberg JO, Weitzberg E, Gladwin MT. The nitrate-nitrite-nitric oxide pathway in physiology and therapeutics. Nat. Rev. Drug Discov. 2008; 7:156-67.

2. Larsen FJ, Ekblom B, Sahlin K, Lundberg JO, Weitzberg E. Effects of dietary nitrate on blood pressure in healthy volunteers. N. Engl. J. Med. 2006; 355:2792-3.

3. Larsen FJ, Weitzberg E, Lundberg JO, Ekblom B. Effects of dietary nitrate on oxygen cost during exercise. Acta. Physiol. (Oxf.). 2007; 191:59-66.

4. Coggan AR, Broadstreet SR, Mahmood K, et al. Dietary nitrate increases $\mathrm{VO}_{2}$ peak and performance but does not alter ventilation or efficiency in patients with heart failure with reduced ejection fraction. J. Card. Fail. 2018; 24:65-73.

5. Pawlak-Chaouch M, Boissière J, Gamelin FX, Cuvelier G, Berthoin S, Aucouturier J. Effect of dietary nitrate supplementation on metabolic rate during rest and exercise in human: a systematic review and a metaanalysis. Nitric Oxide. 2016; 53:65-76.
6. Ferguson SK, Hirai DM, Copp SW, et al. Impact of dietary nitrate supplementation via beetroot juice on exercising muscle vascular control in rats. J. Physiol. 2013; 591:547-57.

7. Casey DP, Treichler DP, Ganger CT4th, Schneider AC, Ueda K. Acute dietary nitrate supplementation enhances compensatory vasodilation during hypoxic exercise in older adults. J. Appl. Physiol. 2015; 118:178-86.

8. Jones AM. Dietary nitrate supplementation and exercise performance. Sports Med. 2014; 44(1 Suppl):S35-45.

9. Jones AM. Influence of dietary nitrate on the physiological determinants of exercise performance: a critical review. Appl. Physiol. Nutr. Metab. 2014; 39:1019-28.

10. Haider G, Folland JP. Nitrate supplementation enhances the contractile properties of human skeletal muscle. Med. Sci. Sports Exerc. 2014; 46:2234-43.

11. Coggan AR, Leibowitz JL, Kadkhodayan A, et al. Effect of acute dietary nitrate intake on maximal knee extensor speed and power in healthy men and women. Nitric Oxide. 2015; 48:16-21.

12. Whitfield J, Gamu D, Heigenhauser GJF, et al. Beetroot juice increases human muscle force without changing $\mathrm{Ca}^{2+}$-handling proteins. Med. Sci. Sports Exerc. 2017; 49:2016-24.

13. Domínguez R, Garnacho-Castaño MV, Cuenca E, et al. Effects of beetroot juice supplementation on a 30-s high-intensity inertial cycle ergometer test. Nutrients. 2017; 9:E1360. doi: 10.3390/nu9121360.

14. Coggan AR, Broadstreet SR, Mikhalkova D, et al. Dietary nitrate-induced increases in human muscle power: high versus low responders. Physiol. Rep. 2018; 6:e13575, https://doi.org/10.14814/phy2.13575.

15. Rimer EG, Peterson LR, Coggan AR, Martin JC. Increase in maximal cycling power with acute dietary nitrate supplementation. Int. J. Sports Physiol. Perform. 2016; 11:715-20.

16. Kramer SJ, Baur DA, Spicer MT, Vukovich MD, Ormsbee MJ. The effect of six days of dietary nitrate supplementation on performance in trained CrossFit athletes. J. Int. Soc. Sports Nutr. 2016; 13:39 https://doi.org/10. 1186/s12970-016-0150-y.

17. Jonvik KL, Nyakayiru J, van Dijk JW, et al. Repeated-sprint performance and plasma responses following beetroot juice supplementation do no differ between recreational, competitive, and elite sprint athletes. Eur. J. Sport Sci. 2018; 7:1-10.

18. Coggan AR, Leibowitz JL, Spearie CA, et al. Acute dietary nitrate intake improves muscle contractile function in patients with heart failure: a doubleblind, placebo-controlled, randomized trial. Circ. Heart Fail. 2015; 8:914-20.

19. Coggan AR, Broadstreet SR, Leibowitz JL, et al. Dietary nitrate and muscle power with aging. Med. Sci. Sports Exerc. 2017; 49:S816.

20. Justice JN, Johnson LC, DeVan AE, et al. Improved motor and cognitive performance with sodium nitrite supplementation is related to small metabolite signatures: a pilot trial in middle-aged and older adults. Aging (Albany NY). 2015; 7:1004-21.

21. Montenegro MF, Sundqvist ML, Nihlén C, et al. Profound differences between humans and rodents in the ability to concentrate salivary nitrate: implications for translational research. Redox Biol. 2016; 10:206-10.

22. Hernández A, Schiffer TA, Ivarsson N, et al. Dietary nitrate increases tetanic $[\mathrm{Ca} 2+] \mathrm{i}$ and contractile force in mouse fast-twitch muscle. J. Physiol. 2012; 590:3575-83.

23. Vandeboom R. Modulation of skeletal muscle contraction by myosin phosphorylation. Compr. Physiol. 2017; 171-212.

24. Stamler JS, Meissner G. Physiology of nitric oxide in skeletal muscle. Physiol. Rev. 2001; 81:209-37.

25. Maréchal G, Gailly P. Effects of nitric oxide on the contraction of skeletal muscle. Cell. Mol. Life Sci. 1999; 55:1088-102.

26. Piknova B, Park JW, Kwan Jeff Lam K, Schechter AN. Nitrate as a source of nitrite and nitric oxide during exercise hyperemia in rat skeletal muscle. $\mathrm{Ni}$ tric Oxide. 2016; 55-56:54-61.

27. Gilliard CN, Lam JK, Cassel KS, Park JW, Schechter AN, Piknova B. Effect of dietary nitrate levels on nitrate fluxes in rat skeletal muscle and liver. $\mathrm{Ni}$ tric Oxide. 2018; 75:1-7.

28. Nyakayiru J, Kouw IWK, Cermak NM, Senden JM, van Loon LJC, Verdijk LB. Sodium nitrate ingestion increases skeletal muscle nitrate content in humans. J. Appl. Physiol. 2017; 123:637-44.

29. Fulford J, Winyard PG, Vanhatalo A, Bailey SJ, Blackwell JR, Jones AM. Influence of dietary nitrate supplementation on skeletal muscle metabolism and force production during maximal voluntary contractions. Pflüger Arch. 2013; 465:517-28. 
30. Hoon MW, Fornusek C, Chapman PG, Johnson NA. The effect of nitrate supplementation on muscle contraction in healthy adults. Eur. J. Sport Sci. 2015; 8:712-9.

31. Coggan AR, Peterson LR. Dietary nitrate and skeletal muscle contractile function in heart failure. Curr. Heart Fail. Rep. 2016; 13:158-65.

32. Tang L, Wang H, Ziolo MT. Targeting NOS as a therapeutic approach for heart failure. Pharmacol. Ther. 2014; 142:306-15.

33. Di Massimo C, Scarpelli P, Di Lorenzo N, Caimi G, di Orio F, Ciancarelli MG. Impaired plasma nitric oxide availability and extracellular superoxide dismutase activity in healthy humans with advancing age. Life Sci. 2006; 78:1163-7.

34. Thompson C, Wylie LJ, Fulford J, et al. Dietary nitrate improves sprint performance and cognitive function during prolonged intermittent exercise. Eur. J. Appl. Physiol. 2015; 115:1825-34.

35. Wylie LJ, Bailey SJ, Kelly J, Blackwell JR, Vanhtatalo A, Jones AM. Influence of beetroot juice supplementation on intermittent exercise performance. Eur. J. Appl. Physiol. 2016; 116:415-25.

36. Thompson C, Vanhatalo A, Jell H, et al. Dietary nitrate supplementation improves sprint and high-intensity intermittent running performance. Nitric Oxide. 2016; 61:55-61.

37. Andrade FH, Reid MB, Westerblad H. Contractile response of skeletal muscle to low peroxide concentrations: myofibrillar calcium sensitivity as a likely target for redox-modulation. FASEB J. 2001; 15:309-11.

38. Murad F. The nitric oxide-cyclic GMP signal transduction system for intracellular and intercellular communication. Recent Prog. Horm. Res. 1994; 49:239-48.

39. Gould N, Doulias PT, Tenopoulou M, Raju K, Ischiropoulos H. Regulation of protein function and signaling by reversible cysteine S-nitrosylation. J. Biol. Chem. 2013; 288:26473-9.

40. Ishii T, Sunami O, Saitoh N, Nishio H, Takeuchi T, Hata F. Inhibition of skeletal muscle sarcoplasmic reticulum $\mathrm{Ca}^{2+}$-ATPase by nitric oxide. FEBS Lett. 1998; 440:218-22.
41. Nogueira L, Figueiredo-Freitas C, Casimiro-Lopes G, Magdesian MH, Assreuy J, Sorenson MM. Myosin is reversibly inhibited by S-nitrosylation. Biochem. J. 2009; 424:221-31.

42. Dutka TL, Mollica JP, Lamboley CR, et al. S-nitrosylation and S-glutathionylation of Cys 134 on troponin I have opposing competitive actions on $\mathrm{Ca}^{2+}$ sensitivity in rat fast-twitch muscle fibers. Am. J. Physiol. Cell Physiol. 2017; 321:C316-27.

43. Stoyanovsky D, Murphy T, Anno PR, Kim YM, Salama G. Nitric oxide activates skeletal and cardiac ryanodine receptors. Cell Calcium. 1997; 21:19-29.

44. Pouvreau S, Allard B, Berthier C, Jacquemond V. Control of intracellular calcium in the presence of nitric oxide donors in isolated skeletal muscle fibres from mouse. J. Physiol. 2004; 560:779-94.

45. Eu JP, Sun JH, Xu L, Stamler JS, Meissner G. The skeletal muscle calcium release channel: coupled $\mathrm{O}_{2}$ sensor and $\mathrm{NO}$ signaling functions. Cell. 2000; 102:499-509.

46. Porter Moore C, Zhang JZ, Hamilton SL. A role for cysteine 3635 of RYR1 in redox modulation and calmodulin binding. J. Biol. Chem. 1999; 274:36831-4 doi:10.1074/jbc.274.52.36831.

47. Durham WJ, Aracena-Parks P, Long C, et al. RyR1 S-nitrosylation underlies environmental heat stroke and sudden death in Y522S RyR1 knockin mice. Cell. 2008; 133:53-65.

48. Maréchal G, Beckers-Bleukx G. Effect of nitric oxide on the maximal velocity of shortening of a mouse skeletal muscle. Pflugers Arch. 1998; 436:906-13.

49. Lai S, Collins BC, Lowe DA. Regulation of skeletal muscle strength by estradiol: myosin regulatory light chain and neuronal nitric oxide synthase. FASEB J. 2013; 27:939.14.

50. Gehlert S, Bloch W, Suhr F. $\mathrm{Ca}^{2+}$ dependent regulations and signaling in skeletal muscle: from electro-mechanical coupling to adaptation. Int. J. Mol. Sci. 2015; 16:1066-95. 